\title{
'Teen mags': helpful or harmful?
}

\author{
Susan Quilliam
}

\section{Background}

Browse along any stationers' shelf and, alongside the stacked copies of Which Car? and Ideal Home, you'll find a flurry of bright pink and turquoise. Teenage magazines ('teen mags') - aimed at girls between the ages of 10 and 16 years - are here to stay.

But, while in my day, Bunty and School Friend were packed with helpful hints on embroidering your gym bag and becoming a prefect, these magazines have a very different profile. 'Be Irresistible: Unlock Your Pulling Power', screams one cover, while another promises: 'Sexy Secrets: 21 Pages of Hot Lads'. Shock. Horror. Surely within these pages lie the reason why Britain's teenage pregnancy rate is so high and why our sexually transmitted infection (STI) rates are soaring?

Certainly that's an opinion held by many. In April of this year, Peter Luff, MP, backed by the Association of Teachers and Lecturers, called for teenage magazines to be statutorily controlled through age restriction. This was the latest salvo from Mr Luff to the magazine publishers. Since 1996, he has constantly accused them of glamourising sex, offering inappropriate role models and encouraging premature, uninformed sexuality. In a recent article in Media Week (June 2004), he called their approach "salaciousness [in the service of] market share and market forces".

\section{The magazines}

So, are these magazines corrupting our children? Your intrepid reporter set out to nail the story. I began at the news stands, popping into my trolley over a dozen teen magazines ranging from Elle Girl (heavily fashion biased) though Smash Hits (heavily music biased) to the stalwarts Bliss, Sugar and Mizz. And yes, they definitely contained sex. Almost all had sexual advice features such as a 'Guide to Talking Dirty'. Almost all had direct sexual advice in their problem page columns, covering such issues as 'I Fancy My Stepbrother' and 'Will Sex Hurt?' All also contained less directly overt sexual material such as interviews with real-life teenage boys about their views on 'one-night stands', and celebrity profiles which included discussion on the stars' love lives.

At first glance this coverage could well be 'too much too soon' for magazines which could be read by girls as young as 12 years old. The information given out in the features does give readers clear directions about the specifics of lovemaking, contraception and STIs. And even the less explicit features could well create peer pressure for youngsters to have sex in order to seem aspirationally 'cool'.

That said, when I looked more closely, the 'shock horror' factor was sometimes only cover-deep. The 'Guide to Talking Dirty' turned out to be a feature about the importance of talking things through with a partner before getting physical - including advice to go to the family planning clinic for support. The one-night stands feature had an overwhelming message of 'don't' - of the nine young men quoted in the article, seven said that they wouldn't want

J Fam Plann Reprod Health Care 2005; 31(1): 77-79

Cambridge, UK

Susan Quilliam, BA, Cert Ed, MNLP, Freelance Writer, Broadcaster and Agony Aunt

Correspondence to: Ms Susan Quilliam.

E-mail: susan@susanquilliam.com a girl to sleep with them on the first night. The problem pages repeated, again and again, the value of co-operation, communication and emotional literacy. And there was heavy stress on age of consent - one advice column mentioned the ' 16 or over' issue four times on a single page.

I was left unsure. Certainly the material these magazines contain is way more sexual than my teenage self used to read back in the 1960s. Conversely, by the time I was 13 - the mean age for reading such magazines and the current age of female puberty in Britain - I was certainly well into the hormonal rush of sexual desire that accompanies adolescence.

And though I myself was well informed on sex education way before said hormonal rush and hence able to emerge from it unscathed, many of my peers weren't. Many of my 13-year-old friends, even back in 1963, were regularly 'heavy petting' lads they had only just met at discos. So perhaps those 1960s magazines should have included a little more guidance, both physiological and emotional. And perhaps it's a good thing that modern magazines do exactly that.

\section{The editors}

That's certainly what the magazines themselves claim. They assert that their coverage is what young people both want and need, that their readers prefer to gain information about sensitive topics through impersonal but trusted sources such as the media and, that without such sources, the younger generation would be not only uninformed but also unresourced.

As Helen Johnston, editor of one of the 'top three' teen mags, Bliss, said on Channel 5's programme 'Joy of Sex Education' (September 2004): "We live in a highly sexualised society, so [teens] are getting messages from all around them. They're looking at pop videos, at the way celebs dress, they're reading tabloids, they're reading adult magazines. They know what's going on but they don't understand the full picture. They're asking for us to teach them ... to help them be forewarned so that they can say no".

... until sex education at home or school improves, teen magazines too often remain the only accurate and responsible source of information.

Lysanne Currie, editorial director at Hachette Filippi, and the person responsible for another of the 'top three' teen mags, Sugar, goes further, defending her position by means of attack. Arguing opposite Peter Luff in Media Week's June 2004 article, she revealed that Sugar had recently commissioned a survey suggesting that $87 \%$ of readers were too embarrassed to talk to their parents about sex. Currie hammered home the point by claiming that: “... until sex education at home or school improves, teen magazines too often remain the only accurate and responsible source of information".

\section{The arbitration panel}

There's an additional justification for the magazines' selfconfidence. They don't simply publish and be damned; they also self-reflect and monitor - and they do so under the aegis of an advisory body largely from outside the industry. 
The Teenage Magazine Arbitration Panel (TMAP) was set up in 1996 to regulate the sexual content of teenage magazines where $25 \%$ or more of the readership is aged 15 years or under. Currently chaired by Fleur Fisher, former head of the British Medical Association's Ethics Science and Information Division, TMAP does include magazine editors, but also representatives from child public health, teenage sexual health, sex education and the law. They carry out monthly monitoring, hold an annual audit, arbitrate on public complaints, run a yearly conference to brief the industry, and publish a series of editorial guidelines.

I read the guidelines - and was impressed by them. They include directives to recommend safer sex, appoint trained counsellors as agony aunts, refer on to professional organisations, discourage underage sex, and encourage readers to turn to trusted adults for advice. Above and beyond these specifics, TMAP seems to be genuinely keen to give what they call "advice in good faith".

\section{The mag format and language are such that teenagers understand - even if they're not ones of which adults approve!}

More, TMAP is actively supported by professional organisations: the Children's Rights Alliance, the National Union of Teachers and the fpa (Family Planning Association) itself. I rang Melissa Dear of the fpa and her endorsement was unequivocal: "We believe that the teen mags offer young people what they need. They deal with issues that aren't dealt with elsewhere. They offer a reliable source of information. Through their agony aunts they give sound advice. In short, these mags offer a hotline for young people's anxieties". But what about 'Sexy Secrets' and 'Pulling Power' - do they not give the wrong impression to young people? Dear was wryly emphatic: "The mag format and language are such that teenagers understand - even if they're not ones of which adults approve!"

\section{The parents}

Well, certainly adults such as Peter Luff don't approve but what say other parents and guardians? For the next stage of my investigation, I sent seven varied extracts from Bliss, Cosmo Girl and Sugar to a small selection of parents with pubescent children.

I had expected at least wariness but instead got cautious approval. "The editors have striven ... to ensure that their quotes by and large take the moral/responsible/legal line." In addition, parents very much confirmed the magazines' claim that teenagers "hunger for information" - and that, if it isn't available from the magazines, teenagers either won't get that information at all, or will get it from unreliable sources.

But hold on. Shouldn't the parents themselves be providing the reliable information source - shouldn't they be the ones teaching their children the facts of life? The parents I spoke to were indeed all attempting to do that but they felt insecure about their own ability to succeed, typically because their children didn't always accept the proffered lessons. When you're 13 and rising, Mum and Dad can have a very low credibility rating!

The parents' key criticism of the magazines' approach was not of the content but the age targeting. They queried how old young people should be when they learn about sexuality, particularly as youngsters mature at different ages. So, as one Mum pointed out, a magazine targeted at the $12-16$ years age range could be appropriately aimed at some 12-year-olds but way over the heads of others.
Linked to this was what parents saw as "relentless targeting" on children to have sex whether they were ready or not. "Missing is any kind of acknowledgement that none of this has to matter if children aren't at an age to be worrying about it." "It is pity that [the feature] didn't point out that ... saying no is fine."

\section{When you're 13 and rising, Mum and Dad can have a very low credibility rating!}

I certainly share this concern. Yes, I see nothing but good in providing children with the information and emotional guidance to handle their own sexuality at a time when, in my own professional (and personal!) experience, urges are so strong. Study after study suggests that far from sex education increasing the likelihood that young people will sleep around, it raises the age of first intercourse and lowers the rate of teenage pregnancy. ${ }^{1-5}$

But could the magazine messages be harmful not by equipping young people for sex but by presupposing them into it? Can young people stand against such a statement of peer norms if they themselves aren't ready to make love?

\section{The teens}

There was only one way to find out. For the final stage of my investigation, I talked to a small selection of teenagers who, away from their parents' prying eyes and ears, gave their opinions on the magazines. And their responses were startling, though perhaps not for the reasons you might think. Instead of being shocked by the teens' free and easy attitude to sexuality, I was taken aback by their balanced, considered and thoughtful observations.

To begin with, they were not phased or put off by what they saw - on the contrary, they were very positive: "I believe in the importance of sexual discussion and advice".

But these positive responses weren't motivated by titillation or a desire to be aroused. On the contrary, these young people offered considered and convincing arguments, which emphatically reflected the magazines' self-justification: "As a society, we are not particularly accepting of unnecessary conversation about sex and 'personal' questions." "In my experience I had very little sex education, only really the biology side of things." "... sex education isn't taught well in schools ... and no one ever listens properly ..." and "magazines are ... a good way of revealing - often anonymously - secret worries...".

\section{In my experience I had very little sex} education, only really the biology side of things.

My respondents weren't uncritical, however; on the contrary, they showed a degree of discrimination and judgement that often matched the adults' comments: "[this was] an obviously rude and blunt question ... not something most fans will want to know." "I don't think that articles that say about people having underage sex should be included in teenage magazines" and "... what irritates me is ... the tendency to talk about boys a lot ... there are plenty of things to do other than date!"

And they put forward their own clear standards for the coverage, standards that make a clear stand for the empowerment that Helen Johnson is claiming that teen mags offer: "It's good for teenagers to know about the consequences of sex". "Frankee sets a great example by 
putting her own sex life on hold until 18." "This ... is good ... because it can make girls feel stronger and more secure about themselves ..." (the latter comment coming from a boy).

... sex education isn't taught well in schools ... and no one ever listens properly ...

In short, the whole impression these young people gave reflects a comment I received from the fpa's Melissa Dear: "The approach you see from many alarmists particularly the right-wing press - underestimates young people. Teens don't read about a sex tip in a magazine and then suddenly go out and action that! They're far more sensible than that".

\section{Final verdict}

What have I learned then, from my review of the teen mag scene? Well, I'm a lot happier than when I started. What's available may seem strong, but it's well thought through by its creators. More importantly, it's well handled by its readers. For me, the reassuring clincher was the teenage reaction. Yes of course every family planning professional in the country sees a stream of uninformed, thoughtless, young people struggling to cope with unwanted pregnancies and STIs - though my guess is that these are the individuals who don't get any form of sex education, in magazines or out of them. But the overwhelming impression I got from my teen respondents was that they wanted the coverage, that they needed it - and that they were mature enough to cope with it.
Teens don't read about a sex tip in a magazine and then suddenly go out and action that! They're far more sensible than that.

Maybe even mature enough to cope because of it. For my final thought was this: in my teens, I wasn't exposed to the explicit coverage of sex that my young interviewees are. But despite my excellent sex education, at 13 I was nowhere near as thoughtful and aware in my attitudes to sexuality as they obviously are. And maybe there's a moral there somewhere.

References

1 Baldo M, Aggleton P, Slutkin G. Does Sex Education Lead to Earlier or Increased Sexual Activity in Youth? Geneva, Switzerland: World Health Organization Global Programme on AIDS, 1993.

2 Fife-Schaw CR, Breakwell GM. Estimating sexual behaviour parameters in the light of AIDS: a review of recent UK studies of young people. AIDS Care 1992; 4: 187-201.

3 Ford NJ. The Socio-Sexual Lifestyles of Young People in the South West of England. Bristol, UK: South Western Regional Health Authority, 1991.

4 NHS Centre for Reviews and Dissemination, University of York, York, UK. Preventing and reducing the adverse effects of unintended teenage pregnancies, Effective Health Care 1991; 3. 1-11. http://www.york.ac.uk/inst/crd/ehc31.pdf [Accessed 8 November 2004].

5 Oakley

Oakley A, Fullerton D, Holland J, France-Dawson M, Arnold S, Kelley P, et al. Reviews of Effectiveness No. 2: Sexual Health Interventions for Young People. London, UK: Social Science Research Unit, 1994.

Editor's Note

Susan’s latest book, Body Language (£12.99, Carlton Books Limited), was published in October 2004.

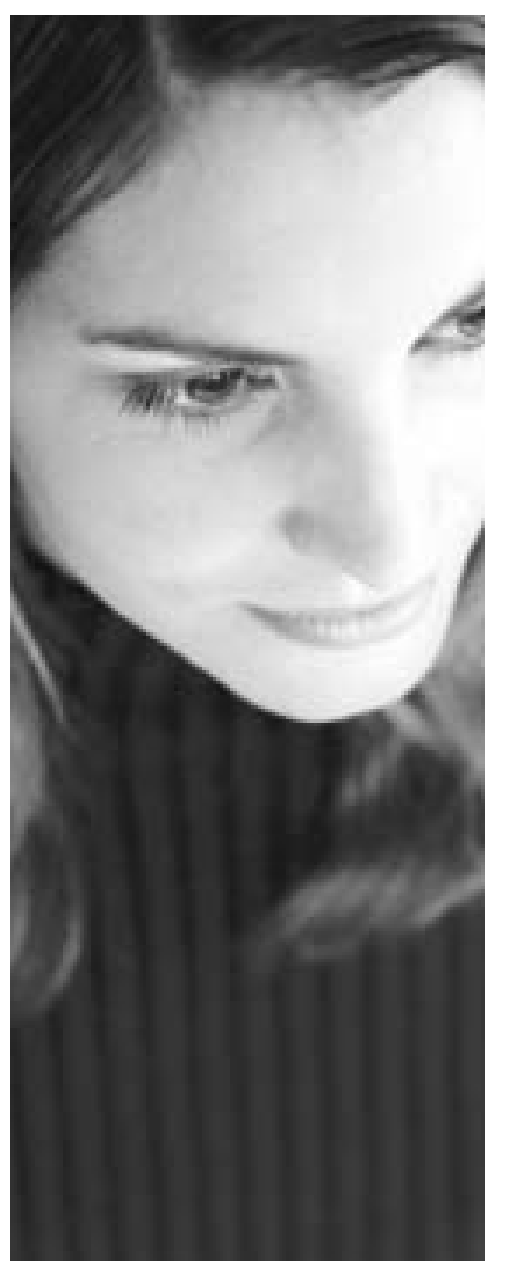

\section{Termination of Pregnancy}

\section{Fast, confidential, caring. The professional choice.}

Marie Stopes International is a leading charity in the field of family planning. We work closely with the NHS to provide termination of pregnancy services and are also happy to accept private referrals.

At centres around the UK we offer a professional and convenient service. You can trust us to take care of the patients you refer. We're discreet, confidential, sympathetic and will do everything we can to make a difficult time easier. Patients can also rely on our full aftercare service including post abortion counselling.

If your patient would like an appointment or if you would like to find out more about us, simply call the number below. We will be happy to send you an information pack containing full details of our services and some easy to use referral forms. Alternatively, you can visit our web site.

Call us on 08453001212 or visit www.mariestopes.org.uk 